\title{
Technology as Terrorism: Police Control Technologies and Drone Warfare*
}

\author{
Jessica Wolfendale \\ Marquette University \\ Forthcoming in Counter-Terrorism, Ethics, and Technology: Emerging Challenges At The \\ Frontiers Of Counter-Terrorism, eds. Adam Henschke, Scott Robbins, and Alastair Reed, \\ Springer 2021
}

Please refer to published version for citation purposes.

\begin{abstract}
$\underline{\text { Abstract }}$
Debates about terrorism and technology often focus on the potential uses of technology by nonstate terrorist actors and by states as forms of counterterrorism. Yet, little has been written about how technology shapes how we think about terrorism. In this chapter I argue that technology, and the language we use to talk about technology, constrains and shapes our moral understanding of the nature, scope, and impact of terrorism, particularly in relation to state terrorism. After exploring the ways in which technology shapes moral thinking, I use two case studies to demonstrate how technology simultaneously hides and enables terroristic forms of state violence: police control technologies and Unmanned Aerial Vehicles (UAVs), or drones. In both these cases, I argue that

\footnotetext{
* This paper benefited greatly from comments from the editors of this volume, Adam Henschke and Scott Robbins. I would also like to thank Risa Brooks, Nicholas Evans, Theresa Tobin, Anthony Peressini, and the faculty and graduate students at the Marquette University Philosophy Department's Weekly Seminar, for their helpful feedback and suggestions.
} 
features of these technologies, combined with a narrative of precision and efficiency, masks the terroristic nature of the violence that these practices inflict and reinforces the moral exclusion of those against whom these technologies are deployed. In conclusion, I propose that identifying acts of terrorism requires a focus on the impact of technologies of violence (whether they are "high tech" or not) on those most affected, regardless of whether users of these technologies conceive of their actions as terrorist.

\section{Introduction}

The topic of this volume is terrorism and technology. Typically, discussions about the relationship between terrorism and technology focus on how new technologies, such as drones (Strawser 2013a; Kaag \& Kreps 2014), artificial intelligence (UN News 2019), social media (Gelzer et al 2019), and surveillance technologies could be used either as a means of fighting terrorism or as a method of terrorism (Gartenstein-Ross et al. 2020).

Few authors, however, recognise how technology shapes and reflects the moral framework through which we think about terrorism, terrorists, and the victims of terrorism - particularly in relation to state terrorism. Instead, the standard view is that "what is good or bad about [technology] is not technologies themselves but the ends to which they are put" (McReynolds 2005, 72). In this chapter I argue that technologies of violence are not simply neutral objects that may be used for good or bad purposes. Instead, the design of these technologies, the contexts in which they are deployed, and the narratives surrounding their use reflect and reinforce biases and frame and limit moral decision-making regarding when and against whom technologies are used. Thus, these technologies profoundly impact our moral understanding of the nature and justification of different 
forms of violence. Section 1 outlines how the concept of technology and technological artefacts themselves create and embody normative associations and values that shape the moral landscape of their use. In Sections 2 and 3, I apply David Rodin's moral definition of terrorism to the case studies of police control technologies and drone warfare. I argue that police control technologies, including riot technologies, stun guns, and tasers, function as a terrorist display that reflects and reinforces the long-standing and deeply entrenched association of criminality with blackness and thus play a crucial "signifying role" in delineating who may be harmed, who is a threat, and who is to be protected. In Section 3, I argue that the US drone program is also a form of terrorism. However, the nature of drone technology, and the accompanying narrative that frames drones as weapons of precision and discrimination, masks the terrorist impact of drone warfare on those subjected to it and contributes to the illusion that drone warfare is objective, precise, unbiased, and even inherently moral.

In both cases, I show how the narrative of technologies of violence as neutral tools masks the terrorist nature of certain kinds of state violence and obscures the power dynamics inherent in that narrative. As will become clear, the view that these technologies are morally neutral or even benign reflects the privileged stance of the users of these technologies. From the perspectives of those who are subjected to these technologies, they are far from morally neutral. Thus, as I argue in the conclusion, identifying acts as terrorist requires focusing on the impact of those acts (whether they are "high tech" or not) on those most affected, regardless of whether those involved in producing these effects conceive of their actions as terrorist. Scholars writing on terrorism and technology must acknowledge that the development and use of technologies of violence is not neutral but 
encodes and reinforces normative judgments about terrorism, the moral status of victims of terrorism, and moral responsibility for terrorism.

\section{The concept of technology}

We could define "technology" simply as any human made artefact, including everything from basic tools, "specific devices and inventions," to "complex sociotechnological systems" (Rhodes 2007, 547). But if that is all we mean by "technology," there is no reason to think that the relationship between technology and terrorism poses any unique ethical questions: of course terrorists use technology (guns, planes, mobile phones, bombs, and so forth) to achieve their goals, to varying degrees of success, and of course technology can be employed to fight terrorism. But this way of thinking about the relationship between technology and terrorism ignores the fact that "technology" is not a neutral term but brings with it a range of concepts and associations that are not always made explicit, but that shape our moral thinking in important ways.

\subsection{Technology and moral mediation}

It is a mistake to see technologies as inert objects with which we interact with the world. Instead, as Peter-Paul Verbeek argues, technologies "give shape to what we do and how we experience the world. And in doing so they actively contribute to the ways we live our lives" $(2011,1)$. Technologies "mediate moral decisions and help to attribute responsibilities and instil norms" (Verbeek 2011, 2)

This process occurs along several dimensions. Firstly, from when it first gained widespread usage in the late $19^{\text {th }}$ century, the concept of technology was associated with the idea of moral and social 
progress (Marx 1997, 969). This is particularly true in relation to technologies of state violence. To illustrate, in the US, each time a new technology of execution (electric chair, gas chamber, lethal injection) was introduced, it was heralded as offering not only a more efficient means of killing, but a more humane means of killing, thereby conflating technological capacity with moral values. For example, one newspaper described the electric chair as providing a death that was "less painful and more dignified" (Linders et al 2020, 4, emphasis added). Another claimed that "science has devised a much more effective and decent way of putting to death" (Linders et al 2020, 12, emphasis added). Similar statements were made about the gas chamber and lethal injection. Yet, in each case the supposed humanity of the new technology was undermined by the botched executions and visible suffering that occurred almost as soon as the technology was put into use, leading to a further (futile) search for a technological solution to the problem of capital punishment (Linders et al 2020,22) — a search that obscures the irresolvable moral tension in the very concept of a humane execution. As we shall see, a similar moral tension, and the use of a narrative that conflates efficiency with moral progress, also underlies the search for technological solutions to police brutality, and in the development and use of drones.

The association between technological development and moral and social progress also plays out in the distinction between "high-tech" and "low-tech." "High-tech" is associated with civilization and progress, whereas "low-tech" suggests primitive societies and backward moral thinking. As Phillip McReynolds argues in his discussion of the discrepancy between Al Qaeda's low-tech terrorism and the high-tech counterterrorism response of the United States,

"the low technology of terrorism [suicide bombs, box cutters, and so forth] bears the marks of a lack of respect for human life in general, for individualism, and for freedom whereas 
high technology as located within an ideology of progress is understood of leading directly to a greater respect for human life, individuality, and freedom ... the notion of high-tech violence as opposed to the more direct, low-tech variety carries as sense of moral superiority" $(2005,82-83){ }^{1}$

Secondly, technology organises "situations of choice and suggest[s] the choice that should be made" (Verbeek 2011, 5). As Bruno Latour explains, technology can "authorise, make possible, encourage, make available, allow, suggest, influence, hinder, prohibit, and so on." (Latour 2005, 104, in Schwartz 285). Different technologies amplify some aspects of the world and reduce the prominence of others, and thereby "direct" or "organise" our perceptions in particular ways (Verbeek 2011, 11). This has significant, but often underappreciated, moral implications. For example, the mere availability of a technology may be viewed as a moral reason for selecting it, as occurred when the Dallas Police Department used a bomb-disposal robot carrying C-4 explosives to kill a man who had shot five officers. In defending this action, Police Chief David Brown stated that "We had no choice, in my mind, but to use all tools necessary" (Schwarz 2018, 281, emphasis added). The availability of the robot thereby played a role in "directing ... moral deliberations" (Schwarz 2018, 281) and was "influential in justifying such extreme means"

\footnotetext{
${ }^{1}$ McReynolds attributes this to the ways in which high-tech weapons, such as drones and longrange missiles, make killing seem "less violent ... the more direct connection to it [violence] that accompanies low-tech violence tends to reflect poorly on the human and moral status of the person who carries it out." $(2005,83)$. This distinction is also likely part of the reason why "high-tech" violence, such as that inflicted by drone warfare (discussed in Section 3), is less likely to be described as terrorism. I thank Risa Brooks for suggesting this point.
} 
(Schwartz 2018, 285). Once a technology is utilised in this way, further use of the technology rapidly becomes normalised and justified and diverts attention diverts attention from other possible courses of action: "legitimating the use of a technology is linked to its naturalization" (Qaurooni \& Ekbia 2017, 65). Lorna Rhodes makes this point in her discussion of the technology of solitary confinement: "once the option of isolation exists, it tends to be normalized as a 'common sense' fix for inadequate mental health care, overcrowding, and failure to adequately protect prisoners in the general population." (Rhodes 2007, 551).

Thus, the choice of technology shapes moral decision-making in ways that can lead to a conflation between moral concepts such as justification and non-moral concepts such as efficiency. As Elke Schwarz explains the "moral significance of choosing technological means might make some means that are not necessarily justified seem justified; it might make means that are not absolutely necessary seem necessary, and it might make technological tools that for whatever reason appear to be the most attractive option in a collection of available options seem like the only option" (Schwarz 2018, 284-85). ${ }^{2}$

${ }^{2}$ Schwarz makes this point in relation to the choices of technology in thought experiments to do with justified killing and liability to harm. For example, in her discussion of Gerhard Øverland's thought experiment involving the use of a flamethrower in self-defense that threatens the lives of others nearby, she writes: “Øverland posits that the permissibility of Mary using her flamethrower and killing the occupants of the house depends on how many people would die and how many would be saved. In this case, the cost of the destructive range of the technology at hand is assigned 


\subsection{Technology and bias}

Technologies often embody and reinforce the moral, social, and political norms and biases of those who create and use them. One obvious way this occurs is when an otherwise "neutral" technology is deployed in ways that disproportionately harm members of a certain group as, for example, when police control technologies such as tasers and stun guns are used disproportionality against persons of colour. But biases and norms can also be literally "built in" to technological systems in ways that can cause disproportionate harm to members of minorities and other stigmatized groups.

One way this occurs is through bias in the design and use of algorithms. As Schwarz explains, "how an algorithm functions and how it is trained reflects the values and principles of its intended uses and its designers ... They regularly reflect the aims and intentions of their makers and normalize their positions and priorities (values)" (2018, 292). For example, studies on facial recognition technologies in the context of law enforcement have found that these technologies reflect and reinforce racial bias. Ruha Benjamin describes the scale of this "default discrimination": "At every stage of the process - from policing, sentencing, and imprisonment to parole — automated risk assessments are employed to determine people's likelihood of committing a crime." Yet, multiple studies have found that these automated processes are

to the people in the house, who become 'moral obstacles', despite the fact that the availability of the flamethrower as a specific means of action is entirely invented by the thought experiment" $(2018,284)$. 
"remarkably unreliable in forecasting violent crime" $(2019,81)$. The impact of this encoded bias can be devastating: "Black people are overrepresented in many of the databases faces are routinely searched against" which means that "Black people are more often stopped, investigated, arrested, incarcerated and sentenced as a consequence of facial recognition technology ... Black people are more likely to be enrolled in face recognition systems, be subject to their processing and misidentified by them" (Bacchini \& Lorusso 2019, 326).

The problem of biased algorithms in facial recognition systems is exacerbated by the phenomenon of automation bias (Cummings 2012). Research demonstrates that humans have an unwarranted belief in the neutrality and accuracy of technological systems: "humans have a tendency to disregard or not search for contradictory information in light of a computer-generated solution that is accepted as correct" (Schwarz 2018, 290). This means that the "results" of facial recognition algorithms (and other biased algorithms) are likely to be assumed to be objectively correct, leading to a vicious cycle that reinforces embedded biases and lends them an unwarranted patina of legitimacy (Cummings 2012, 2-3).

Bias can also be literally "built in" to technological systems. Kodak's Shirley card, used as a comparison image to ensure that the colours in a printing look "right", offers an example of this form of bias. In its original form, the Shirley card featured a white woman with "ivory skin, brown hair, and red lipstick" (Liao \& Huebner 2020, 3). But, "[s]ince the model's white skin was set as the norm, darker skinned people in photographs would be routinely underexposed" (Benjamin 2019, 104). The Shirley card thus both reflected its creators' racial biases and then continued use 
of the Shirley card reinforced this bias, calcifying the view that white skin was the ideal aesthetic standard and the standard of "normal" skin tone (see Benjamin 2019, 103-109).

In sum, technologies "mediate moral decisions" (Verbeek 2011, 2), and so shape our moral understanding of our actions by offering (and restricting) choices, reflecting and reinforcing preexisting biases, and through accompanying narratives that frame new technologies in terms of moral values such as dignity and humaneness. As is clear from examples of capital punishment discussed earlier, the narratives that accompany the development and use of new technologies frequently privilege the perspective of users and developers rather than that of those subjected to these technologies. In what follows, I show how this complex dynamic between technology and moral evaluation and decision-making plays out in the context of drone warfare in ways that obscure the impact of drone warfare on those subjected to it- an impact that is, I argue, sufficiently severe to constitute terrorism.

\subsection{What is terrorism?}

What do I mean by terrorism? In this chapter, I adopt elements of David Rodin's moral definition of terrorism. A moral definition is "an analysis of the features of acknowledged core instances of terrorism [such as the 9/11 attacks] which merit and explain the moral reaction which most of us have toward them" $(2004,753)$. Rodin locates the moral opprobrium many of us feel toward terrorism in the fact that core instances of terrorism are characterised by "the use of force against those who should not have forced used against them" $(2004,755)$. He then defines terrorism as "the deliberate, negligent, or reckless use of force against noncombatants, by state or nonstate 
actors for ideological ends and in the absence of a substantively just legal process" $(2004,755) .^{3}$ The reference to force against noncombatants for ideological ends is consistent with many other definitions of terrorism. Rodin's inclusion of reckless and negligent acts in his definition is controversial but given that the case studies I discuss involve intentional actions, I will not weigh in on this controversy here. ${ }^{4}$ Given this definition, we can now turn to the case of police control technologies.

\section{Police control technologies as terrorist display}

Police control technologies include devices such as tasers and stun guns, riot control technologies such as tear gas, rubber bullets, and the use of militarised weapons, tactics, and uniforms "that were once the preserve of military units in war zones" (Dobos 2020, 110). The contexts in which these technologies are used, the class of people against whom they are deployed, and the

${ }^{3}$ Rodin defines "ideological ends" to "signify a commitment to some systematic and socially directed end beyond the motives of fear, anger, lust and personal enrichment, which are the typical motives of common violent crimes" $(2004,756)$. The term "noncombatants" is intended to capture the fact that the victims of terrorism are not engaged in activities that would render them liable to the use of force, such as combat. Thus, attacks against military targets can count as terrorism (2004, 757). Reference to the absence of a "substantively just legal process" is intended to distinguish terrorist violence from the use of force accompanying just legal processes $(2004,759-60)$.

${ }^{4}$ See Woodside 2013 for a critique of Rodin's claim that reckless and negligent acts can count as terrorism. 
justifications offered for their use, reveal much about who is perceived as a threat, who is judged liable to be killed and wounded, and who is judged worthy of protection.

\subsection{Riot control technologies}

\subsubsection{The narrative of threat}

A justifcatory narrative of threat and protection is particularly apparent in the use of riot technologies. This means that the contexts in which riot technologies are not used are just as revealing as the contexts in which they are used. For example, in the wake of the killing of George Floyd, Black Lives Matter (BLM) protesters were subjected to tear gas and other "non-lethal weapons" such as rubber bullets and stun grenades, wielded by police and federal forces clad in militarised riot gear, including face shields, external bullet-proof vests, and knee-high boots. In comparison, the armed white protestors who raided the US Capitol building on January 6, 2021, faced police who were not clad in riot technology and who did not engage in substantial force against them (Williams 2021). This stark and visible disparity in the use of violent control technologies serves a powerful signifying function: BLM protestors are dangerous but white protestors are not, even when engaged in a violent armed insurrection; the technologies of violence and suppression are necessary (and therefore justified) when interacting with BLM protestors, but not when interacting with majority white protestors (Regan 2021). Images of the police response to these different groups, replicated in media coverage of the protests, communicates and reinforces, even more effectively than words or political speeches, the criminalisation of 
blackness $^{5}$ and the belief that people of colour (and those who support them) pose such a threat that they may justifiably be harmed or killed. The visual narrative that accompanies the use of these technologies thereby "symbolically excludes the citizens from the state" (Dobos 2020, 114) and reflects a resurgence of the "escalated force" policy of "a dominant show of force" that governed police responses to anti-war and civil rights protestors in the 1960s (groups also characterized as threats to the state) (Maguire 2015, 75).

\subsubsection{Techno-subjectivity and moral mediation}

The "techno-subjectivity" (Schwarz 2018, 288) of these technologies (how it feels to deploy and wear them) feeds this narrative of threat and mediates the moral decision-making of those who wield them. There is substantial evidence that when police adopt military-style tactics and "start using weapons and equipment that were designed for soldiers in combat" (Dobos 2020, 109), their perception of their role and their relationship with the community is altered, particularly in relation to communities of colour: "pacifying and defeating the enemy becomes more important than protecting and serving the public" (Dobos 2020, 110. See also Regan 2020). In the United States, the adoption of military technology also has a measurable impact on incidents of police killings. One study found that "more than twice as many civilians are likely to be killed by police in a county after its material militarization than before" (Dobos 2020,111). This risk is not distributed evenly among the community, however: "Risk is highest for black men, who (at current levels of risk) face about a 1 in 1,000 chance of being killed by police over the life course. The average

\footnotetext{
${ }^{5}$ As noted in Section 1, this narrative is also embedded and reinforced through the design and use of facial recognition technologies.
} 
lifetime odds of being killed by police are about 1 in 2,000 for men and about 1 in 33,000 for women ... For young men of color, police use of force is among the leading causes of death" (Edwards et al. 2019). ${ }^{6}$ Thus, the deployment of riot control and other militarised technologies reinforces the association of blackness with criminality and directly contributes to the ongoing and pervasive vulnerability of people of colour to violent interactions with criminal justice system. The ready availability of these technologies combined with the contexts in which they are (and are not) deployed thereby creates an ongoing and embedded "feedback loop" that reinforces the belief that people of colour and their supporters represent a dangerous threat. This feedback loop is sustained through at least three mechanisms: the media circulation of visual depictions of riot technologies deployed against people of colour, the language used to describe those against whom the technologies are deployed, and the phenomenological impact on police of wielding these technologies.

\subsubsection{The terrorist impact of riot technologies}

Riot control technologies not only communicate and reinforce the criminalisation of blackness and the moral exclusion of people of colour from the moral and political community; they have concrete traumatic effects that justify the claim that the deployment of these technologies is a form of terrorism. Firstly, the use of these technologies against peaceful protestors communicates a very real threat of physical violence that signifies to those subjected to them that they may be killed or harmed with impunity. Secondly, these technologies cause severe and lasting physical injuries,

\footnotetext{
${ }^{6}$ There are similarly disproportionate rates of police violence against indigenous Australians compared to non-indigenous Australians (Cunneen 2020).
} 
fear, and ongoing trauma (Schwarz 2020). The fact that these technologies are used disproportionately against people of colour and other groups deemed to be outside the moral and political community (such as anti-war protestors in the 1960s and 1970s) indicates that their use is ideologically driven. The ideological nature of these technologies is further evidenced by the origins of their use: "the so-called non-lethal crowd control weapons that are used to disperse protests today have their origins in colonial policing" (Schwarz 2020), where there were used to violently reinforce white supremacist colonial regimes against resistance. As a scholar on the history of tear gas argues, these technologies (then and now) were "deployed to both physically and psychologically destroy people engaging in resistance" (quoted in Schwarz 2020). The impact of these technologies and the way these technologies are deployed, therefore, clearly meets Rodin's definition of terrorism as "the use of force against those who should not have force used against them" that serves an "ideological end" (Rodin 2004, 753). ${ }^{7}$ Give the role of these technologies in creating and sustaining the long-standing and deeply entrenched criminalisation of blackness and the vulnerability of people of colour to police violence, it is not a stretch to say that these technologies are part of a broader system of terrorist control of people of colour. This is also demonstrated by the use and development of tasers and stun guns.

\footnotetext{
${ }^{7}$ Someone might object that violent protesters count as combatants and so these technologies do not target "those who should have force used against them." However, riot technologies are often used against peaceful protestors and there is little to no attempt to restrict the use of force to those who act violently. Additionally, the visual communication of the threat of violence is indiscriminate in its impact.
} 


\subsection{Tasers and stun guns}

\subsubsection{The narrative of effectiveness and humaneness}

While the use of riot technologies is accompanied by (and reinforces) a narrative that focuses on threat, the narrative accompanying the development and use of stun guns and tasers by police appeals to the values of humanness and effectiveness, in a way similar to the narrative that accompanied the development of new execution technologies. When tasers were first introduced as police control technologies, for example, they were touted as being "safe, effective alternatives to ... lethal force" (Sierra-Arévalo 2019, 421) that would solve the ongoing problem of the disproportionate use of excessive (sometimes lethal) force by police against people of colour. (Similar claims have been made about body cameras.) Yet, the problem of excessive force has not in fact diminished (Levin 2020). Instead, the availability of tasers (and stun guns) gave police officers an option they did not previously have, and one that was framed in morally positive terms as non-excessive and humane. But, just as describing new execution technologies as humane did not in fact make executions more humane, the framing of tasers as non-excessive did not in fact mitigate police of force. ${ }^{8}$

This illustrates how describing tasers as a technological solution to the problem of excessive police violence implies that the problem of excessive force is a technological problem that requires a technological solution, and not a problem arising from the longstanding and well documented framework of racism that underpins and structures policing interactions with (and attitudes toward) people of colour in the US (Swartzer 2019).

\footnotetext{
${ }^{8}$ I thank Scott Robbins for suggesting this point.
} 


\subsubsection{The terrorist impact of tasers and stun guns}

Those who defend the use of tasers and stun guns may frame them as technologies of non-lethal restraint and control that can (if properly used) "not appear cruel or beneath human dignity" (Rejali 2003, 157). But the widespread acceptance and normalisation of the use of stun guns and tasers masks the history of these devices in the contexts of torture and the control of animals; a connection that is apparent to those who are subjected to these devices. From the victim's perspective, electric control technologies do not signify respect for their dignity, a reduction in force, or a humane method of control. As Lorna Rhodes relates, prisoners in Supermax prisons (where stun guns are used as control mechanisms), "speak of these technologies as particularly degrading both for their extreme intrusion into the body (they cause muscle weakness as well as pain) and for their association with the control of animals" $(2007,556)$. But, the victims' experiences of these technologies as degrading, dehumanizing, and torturous is masked by the dominant narrative of efficiency and humaneness that frames their use. Thus, this narrative both reinforces and hides the true function of these technologies and privileges the perspectives of users above those of those who are subjected to them.

The association of tasers and stuns guns with torture (a long-standing method of state terrorism) is also clear from the history of these devices in the context of state torture. As Darius Rejali explains, stun guns and other electric devices are popular in states that use torture because, like other "modern" torture techniques (such as sensory deprivation), they "cause suffering and intimidation without leaving much in the way of embarrassing long-term visible evidence of brutality" (2003, 153). In the context of torture, the use of these technologies is not driven by a concern for human 
dignity, but by a desire to avoid charges of human rights violations. Given this history, the widespread acceptance and availability of electric control technologies in the context of law enforcement is astonishing. It represents "an incredible sociotechnical achievement, the work of corporations, politicians, and engineers who have woven this technology into the fabric of everyday life, creating instruments, markets, citizens, and consumers" (Rejali 2003, 154-55). As with riot technologies, those against whom this technology is wielded (who are disproportionately prisoners and people of colour, and those who threaten the state in other ways) are thus "marked out" as deserving or requiring such violent treatment. The use of these technologies (as with the deployment of riot technologies) thereby operates as what Rejali calls "a civic marker" $(2003,154)$ delineating the moral boundaries of civic membership and moral concern through the infliction of instruments associated with terror and torture.

\subsection{Implications}

The above discussion has several implications for understanding the relationship between police control technologies and police use of force. Firstly, any ethical analysis of policing technologies must address how some technologies directly "encode" racial bias (as with facial recognition algorithms). Secondly, such an analysis must also recognise how the contexts in which these technologies are used, and the narratives accompanying their use, shape and constrain the moral decision-making of police officers (and policy makers) in ways that reflect and reinforce an underlying framework of racism. This means that the problem with riot technologies, tasers, and stun guns is not a problem that can be solved by better training or new policies about the contexts of their application. As we have seen with the failure of body cameras and implicit bias training to reduce rates of police violence against people of colour (Levin 2020), unless the deeply embedded 
racist structure of policing in America is confronted and addressed, police technologies will continue to be utilised in ways that reinforce that racist structure and terrorize and threaten the lives and welfare of people of colour. It is for this reason that the "defund the police" movement has gained traction over the last year - a movement that calls for moving state and federal funding and resources from the police and criminal justice system to (for example) social services, public education, mental health services, and affordable housing. This would, it is argued, not only reduce crime rates but would increase the safety and wellbeing of all citizens, and particularly people of colour. Such a move is arguably justified not only economically (Perry et al. 2020) but would also go some way to addressing the underlying issue (one I cannot address in detail here) that terrorist policing practices against people of colour undermine the very basis of the state's authority to use force against its own citizens in a criminal justice context. ${ }^{9}$

\section{Drone warfare}

${ }^{9}$ In many philosophical accounts, the basis for the state's authority to use force against its own citizens to prevent and punish crime is a social contract model (e.g., see Brettschneider 2007). Thus, if police actions and the criminal justice system threaten rather than protect citizens, this undermines the fundamental basis for the legitimacy of such systems. Just as Adam Henschke and Tim Legrand have argued in relation to counter-terrorism policies, we need to ensure that the technologies being used by police do not in fact run counter to the values that underpin and justify the monopoly of power granted to the state (Henschke \& Legrand 2017). I thank the editors of this volume for raising this concern. 
As with the case of police control technologies, the terrorist nature of drone warfare results from the combination of features of drone technology (the capacity for long-term surveillance and the use of algorithmic targeting decisions), the contexts in which drones are deployed, and the impact on those who are subjected to drone surveillance and targeting. This terrorist impact is masked by a narrative that frames the use of drones as morally neutral, even morally good. But whereas the narrative associated with police control technologies emphasised threat protection, control, and humaneness, the narrative that dominates military and political discourse about drones emphasises precision and discrimination. ${ }^{10}$ As the Center for Civilians in Conflict reports, "as covert drone strikes by the United States become increasingly frequent and widespread, reliance on the

${ }^{10}$ There is a substantial philosophical literature on the ethics of drones (see, for example, Kaag \& Kreps 2014 and Strawser 2013a), which I do not have space to discuss here. Ethical issues raised by authors include concerns about the asymmetry of drone warfare (Killmister 2008; Steinhoff 2013), the impact of drone warfare on the moral equality of combatants (Skerker et al 2020), the moral disengagement of drone operators (Sharkey 2010, 371-72), drone operators' moral responsibility (Sparrow 2007; van der Linden 344), and the effect of drone warfare on conceptions of traditional military virtues (Sparrow 2013). Several authors regard the ethics of drone use as no different from the ethics of any long-range technology (Lucas 2013; Kershnar 2013). For example, George Lucas argues that, "[a]s with most exotic new technologies, the novelty [of drones] blinds us to the fact that the moral issues involved are entirely familiar and conventional and not appreciably different from those associated with the development of previous and current weapons technology" $(2013,211)$. 
precision capabilities and touted effectiveness of drone technology threatens to obscure the impact on civilians" $(2012,7)$. This narrative, and the features and context of drone use, thereby serve to "morally mediate" (Verbeek 2011,2) the use of drones by constraining moral choices around drone use, shaping the moral perception of users, policy makers, and the public about the nature and justification of drone use, and "marking out" the targets of drone attacks as warranting the use of force against them.

This means that the terrorist nature of drone warfare only becomes evident when we shift our focus from the narrative and associated moral framework that dominates discussion of drones to the impact of the drone program on those who are subjected to it. First, however, we need to clarify the current scope of the US drone program.

\subsection{The US drone program}

The use of drones as a means of killing suspected and known members of Al Qaeda and other terrorist and militant organisations began under the Bush administration, expanded under the Obama administration (Kaag \& Kreps 2014, 3-4), and expanded further under the Trump administration. According to one report, "As of May 18, 2020, the Trump administration had launched 40 airstrikes in Somalia in 2020 alone." In contrast, "from 2007 through 2016, the administrations of George W. Bush and Barack Obama conducted 41 airstrikes in Somalia total.” (Atherton 2020). Additionally, the Trump administration broadened the designation of "battlefields" to include areas of Yemen and Somalia, thereby loosening the restrictions on drone 
targeting in those areas (Atherton 2020) ${ }^{11}$ and simultaneously "removing the reporting requirement for causalities outside of designated battlefields" (Atherton 2020). This led to a dramatic increase in the numbers of civilian casualties of drone strikes: "In 2019, more Afghan civilians were killed in airstrikes than at any time since early 2002" (Crawford 2020, 2). While the Biden Administration has introduced some restrictions on drone use, including temporarily suspending the use of drones outside war zones (Savage \& Schmidt 2021), it remains unclear what the scope of these changes will be or how, for example, targeting decisions within war zones will be made. Thus, it is clear is that the drone program will be ongoing and there will continue to be little transparency about the impact of drone warfare on those most affected by it.

\subsection{Drone warfare as terrorism}

\subsubsection{The narrative of precision and discrimination}

From their introduction drones have been heralded as "precision weapons" that allow war to be conducted in a more humane way:

"US intelligence officials tout the drone platform as enabling the most precise and humane targeting program in the history of warfare. President Obama has described drone strikes as "precise, precision strikes against al-Qaeda and their affiliates."

11 The Obama administration's Presidential Policy Guidance (PPG) designated looser targeting restrictions for battlefields and tighter ones for nonbattlefields, to allow drones greater freedom in "providing support fire for soldiers in firefights in places such as Afghanistan, while holding tighter restrictions for targeted killing flights in places where the United States did not actively deploy troops on the ground, such as Yemen or Somalia" (Atherton 2020). 
Leon Panetta, Secretary of Defense, has emphasized that drones are "one of the most precise weapons we have in our arsenal," and counterterrorism adviser John Brennan has referred to the "exceptional proficiency, precision of the capabilities we've been able to develop." (Center for Civilians in Combat 2012, 35).

As a result of this narrative, "public concerns with civilian casualties in targeted killing campaigns — concerns that are generally weak or even nonexistent to begin with—are put to rest" (van der Linden, 2016, 335). ${ }^{12}$ As we saw with the language that accompanied the development of new execution technologies, this emphasis on precision conflates a technological value with a moral value ("humaneness" or "dignity"). The view that the technical capacity of drones to distinguish between targets is also a moral capacity is shared by some philosophers. Bradley Strawser, for example, argues that a drone's capacity to discriminate between targets combined with the fact that drone use reduces the risk to the operator to essentially zero means that "we are morally required to use drones over ... manned aircraft to prevent exposing pilots to unnecessary risk" (2013b, 18).

\footnotetext{
${ }^{12}$ It is extremely difficult to know the precise number of civilians who have been killed by drone strikes. This is a result of a combination of factors, including difficult terrain that makes on-theground verification impossible, and the ways in which the category of "militant" is sometimes used to describe any "military-aged male" killed in a strike (Center for Civilians in Combat 2012). However, my argument for the terrorist nature of drone warfare does not rest only on the numbers of civilians who are killed.
} 
However, conflating drones' technical capacity for precision targeting with the moral distinction between combatants and noncombatants not only sustains and reinforces an unfounded complacency about the morality of drone strikes but also obscures the reality of who is targeted by drones and for what reasons. As Harry van der Linden notes, "precision in finding and hitting the target does not imply that there is precision in the selection of the target" $(2016,336$, emphasis in original). John Kaag and Sarah Krepps make the same point: "The distinction between militants and non-combatants ... is a normative one that machines cannot make" $(2014,134)$. Put simply, we cannot assume that the categories of combatant and noncombatant are either clearly defined or justly applied by drone operators and/or political and military decision-makers in the drone program. In fact, we have good reason to doubt that this is the case. For example, claims by US officials in the Obama administration that drones strikes caused very few civilian casualties (Center for Civilians in Combat 2012,31) were complicated by the fact that these assertions were based on "a narrowed definition of 'civilian,' and the presumption that, unless proven otherwise, individuals killed in strikes are militants" (Center for Civilians in Combat 2012, 32). As I argue below, the assumption that the targets of drone strikes are chosen based on clear and justly applied categories of combatant and noncombatant is extremely problematic.

\subsubsection{Bias and the moral mediation of drone technology}

In Section 1.3, I explained how bias can be "built in" and reinforced by technology in multiple ways, from the design of algorithms and the physical features of technologies, to choices about when and against whom technologies are deployed. These forms of bias can become entrenched because of the normalising and self-justifying effects of repeated use of a technology in a specific context against specific groups of people, combined with the phenomenon of automation bias - 
the tendency of users and designers of technologies to assume that the "answers" provided by technological systems are both objective and correct (Cummins 2013). In the cases of drones, bias is evident both in the algorithms that are used to select the targets of drone strikes and in how the class of acceptable targets (who are almost exclusively non-white people) has expanded far beyond any plausible definition of "combatant." This bias is most apparent in the use of drones for signature strikes.

Unlike targeted strikes, where the identity of the target is confirmed before a strike is permitted, signature strikes may be initiated on the basis of perceived patterns of suspicious behaviour: "Signatures may encompass a wide range of people: men carrying weapons; men in militant compounds; individuals in convoys of vehicles that bear the characteristics of al-Qaeda or Taliban leaders on the run, as well as 'signatures' of al-Qaeda activity based on operatives' vehicles, facilities, communications equipment, and patterns of behavior" (Center for Civilians in Combat 2012, 33). But the value of signature identifications depends on a host of normative and culturally biased assumptions about what counts as "suspicious" behaviour. ${ }^{13}$ As Elke Schwarz argues, the use of algorithms to determine the targets of signature strikes "summon[s] the perception that patterns of normality (benign) and abnormality (malign) can be clearly identified" $(2018,288)$.

\footnotetext{
${ }^{13}$ As related in The Civilian Impact of Drones, "As one Yemeni official said, 'Every Yemeni is armed...so how can they differentiate between suspected militants and armed Yemenis?"' (2012, $33)$.
} 
However, as we saw with the use of facial recognition algorithms in law enforcement, the success of such algorithms in correctly ascertaining and predicting malign intent is highly questionable. ${ }^{14}$ Yet, when combined with the phenomenon of automation bias, the "output" of the algorithms used for signature strikes is unlikely to be questioned. This then further reinforces the belief that the mere presence of "suspicious" behaviour (defined based on culturally biased assumptions) provides sufficient evidence of malign intent to justify the use of lethal force. The decision to resort to lethal force is then framed as the "right" or most "logical" response to the perceived threat because "the drone can only execute a limited range of actions vis-à-vis a suspect (survey, pursue or kill). A suspect cannot surrender or persuade the technology of their non-liability to harm" (Schwarz 2018, 288). Thus, the combination of embedded bias in targeting algorithms and the limits of drone technology constrains and shapes the moral choices of users and alters the justificatory framework used to assess the morality of drone warfare. These moral choices and justificatory framework are then normalised via further use of drones combined with the narrative of precision and discrimination discussed above. In particular, this process reinforces and normalises the view that a person may be killed not because they are currently engaged in combat or are known to be part of a militant group, but merely because their behaviour resembles that of someone who might be a future threat. The technology translates "probable associations between

${ }^{14}$ It is also very difficult to know how the veracity of signature strikes could be ascertained, not only because the targets are not known by name (but are chosen merely based on supposedly suspicious behavior), but also because of the factors that impede identification of drone victims in general, noted in footnote 12 . 
people or objects into actionable security decisions" (Amoore 2009, 52). This represents an extraordinary broadening of the concept of a combatant that has devastating consequences:

US experiences in Afghanistan illustrate the risks of targeting with limited cultural and contextual awareness. On February 21, 2010, a large group of men set out to travel in convoy. They had various destinations, but as they had to pass through the insurgent stronghold of Uruzgan province, they decided to travel together so that if one vehicle broke down, the others could help. From the surveillance of a Predator, US forces came to believe that the group was Taliban. As described by an Army officer who was involved: "We all had it in our head, 'Hey, why do you have 20 military age males at 5 a.m. collecting each other?'... There can be only one reason, and that's because we've put [US troops] in the area." The US forces proceeded to interpret the unfolding events in accordance with their belief that the convoy was full of insurgents. Evidence of the presence of children became evidence of "adolescents," unconfirmed suspicions of the presence of weapons turned into an assumption of their presence. The US fired on the convoy, killing 23 people. (Center for Civilians in Combat 2012, 47)

The fact that there is so little public outcry or even discussion about this aspect of the drone program reveals how normalised the use of drones in this way has become. The killing of people based purely on biased and highly unreliable computer-predicted assumptions about the meaning of their behaviour is taken for granted to such an extent that it is rarely deemed worthy of comment. Indeed, the combination of the narrative of discrimination, drone technology, and the processes of 
moral mediation discussed above has created a situation where the ongoing killing and maiming of non-white people based on biased assumptions of threat has come to seem both morally acceptable and even necessary. ${ }^{15}$ As Elke Schwartz explains, "set against a background where the instrument is characterised as inherently wise, the technology gives an air of dispassionate professionalism and a sense of moral certainty to the messy business of war" $(2018,88)$. This "moral certainty" is sustained and reinforced by the "high-tech" nature of drone operations and the narrative of precision and efficiency described above and effectively masks the reality of the terrorist impact of drones on the victims.

\subsubsection{The terrorist impact of drone warfare}

As discussed above, the use of signature strikes significantly increases the risk that noncombatants will be killed and wounded and reinforces the view that merely suspicious behaviour warrants the use of deadly force. But this is only one reason why the current drone program is terrorist. Even if drone strikes only killed known targets, ${ }^{16}$ the impact of living under drone surveillance affects everyone in the area under surveillance, whether they are targets or not. Unlike other long-range

${ }^{15}$ The killing of non-white known targets is also largely unquestioned and normalised, even when the targets are chosen for the purposes of punishment and retaliation (which are not legitimate reasons for killing in just war theory), as was the case with the recent retaliatory drone strike in Syria (Cooper \& Schmitt 2021).

${ }^{16} \mathrm{I}$ am leaving aside the important question of whether drone strikes against known targets are permissible. My argument is that even if they are, this does not mitigate the terrorist impact of drone warfare. 
weapons systems, "only drone killing involves detailed surveillance of the target, including poststrike observation" (van der Linden 2016, 345-46),

The Civilian Impact of Drones report produced by the Center for Civilians in Combat and the Columbia Law School Human Rights Clinic outlines the traumatic effects of living under drone surveillance. ${ }^{17}$ Firstly, drones engaged in surveillance are constantly visible and audible to all those being surveilled, regardless of whether they are targets or not. As van der Linden describes, "[e]veryone is swept up in the surveillance, and living under drones is living under constant fear since, even as a civilian, one may at given moment be wounded or killed" (2016, 351-52). In an important sense, then, "drones are in their psychological impact indiscriminate weapons" (van der Linden 2016, 351). This psychological impact is extremely traumatic. An interviewer for a UK charity spoke to a Pakistani man who "saw 10 or 15 [drones] every day. And he was saying at night-time, it was making him crazy, because he couldn't sleep. All he was thinking about at home was whether everyone was okay. I could see it in his face. He looked absolutely terrified" (Center for Civilians in Combat 2012, 24).

Because of the secrecy of the drone program, those living under drone surveillance may have no idea who is being targeted or the basis on which targets are selected. This uncertainty compounds this constant fear that one (and one's family and loved ones) may be killed or wounded:

${ }^{17}$ The report Living Under Drones, produced by Stanford University and NYU, also details the psychological trauma caused by living under drones (2012, 55-99). 
"With US targeting criteria classified, civilians in Pakistan, Yemen, and Somalia do not know when, where, or against whom a drone will strike. The US policy of 'signature strikes' ... substantially compounds the constant fear that a family member will be unexpectedly and suddenly killed. A civilian carrying a gun, which is a cultural norm in parts of Pakistan, does not know if such behavior will get him killed by a drone” (2012, 29).

This perfectly illustrates the "intrusion of fear into everyday life" that Michael Walzer identifies as one of the key moral harms of terrorism (2001). ${ }^{18}$ The terrorism of drone warfare thus lies not only in the direct physical violence inflicted by drone attacks (which may often kill and maim noncombatants) but also in how drone warfare creates and promulgates a constant, indiscriminate, and terrifying fear of attack.

Compounding the harm of drone warfare is the fact that those who survive a drone attack have no way of discovering who attacked them. They are denied access to the norms of accountability: "For victims in particular, there is no one to recognize, apologize for, or explain their sorrow; for communities living under the constant watch of surveillance drones, there is no one to hold accountable for their fear" (Center for Civilians in Conflict 2012, 24).

\footnotetext{
${ }^{18}$ Walzer is not using this term in a discussion of the drone program, however. I do not think he would agree with my characterisation of the drone program as terrorist.
} 
Despite the devastating toll of drone surveillance on those subjected to it, philosophers writing on drones rarely discuss or even mention this aspect of drone warfare. ${ }^{19}$ For example, Mark Coeckelbergh explores the impact of conducting long-term surveillance on drone pilots' ability to empathise with surveillance subjects (2013) but doesn't mention the experience of those living under surveillance. This focus on the experiences of drone operators rather than on the experiences of those who are subjected to the drone program is typical of most philosophical discussions of this topic. It is also characteristic of media depictions of drone warfare. Whereas media depictions of police riot technologies make visible and reinforce the criminalisation of blackness that underpins the use of those technologies, media depictions of drones almost always show the aircraft themselves, or the cockpits. It is extremely rare that media images show the impact of

${ }^{19}$ Harry van der Linden is one of the few philosophers who does consider the victims' perspective. While he does not describe the drone program as terrorist, he argues that the "deadly surveillance" of drone warfare explains why drones may be "inherently immoral" $(2016,345)$. For van der Linden, drone surveillance is immoral because drone strikes kill people when they are engaged in their ordinary lives - at funerals, while they are under medical care, and in their homes - and this further erodes the distinction between combatant and noncombatant and between battlefield and nonbattlefield. He writes, "operators often become familiar with the target as a person, watch his everyday life, his home, even his family. Thus it seems that a person is killed rather than a combatant or individual engaged in hostile action" $(2016,348)$. For example, he quotes drone pilot Colonel William Tart saying, "We watch people for months. We see them playing with their dogs or doing their laundry. We know the patterns like we know our neighbors' patterns. We even go to their funerals" $(2016,350)$. 
drone attacks. Thus, viewers are constantly reminded of the technological "marvel" of these weapons and rarely confronted with what these weapons do to the people killed and wounded by them and those who must live under the near-constant threat of attack. This focus on drone pilots and drone technology further prioritises the perspective of users over those of victims of these technologies. ${ }^{20}$

In sum, the US drone program meets Rodin's definition of terrorism because it is an ideologically driven ${ }^{21}$ program that inflicts extreme and ongoing psychological and physical trauma on all those who are subjected to drone targeting and surveillance, whether they are the intended targets or not. ${ }^{22}$ Given that we have no reason to believe that the targeting decisions and technological features of the US drone program will substantially change in the foreseeable future, the drone program will likely continue to be a terrorist program under the Biden administration. ${ }^{23}$

${ }^{20}$ I thank Desiree Valentine for raising this issue.

${ }^{21}$ It is ideologically driven because it is in service of US foreign policy, which is a "systematic and socially driven end" (Rodin 2004, 756).

${ }^{22}$ It might be objected that this is true of war in general, given that many of today's wars do not adhere to clear lines between battlefield and nonbattlefield, and between combatant and noncombatant. If that is so, then I would agree that we should consider such wars as inherently terrorist. I thank Scott Robbins for raising this possibility.

${ }^{23}$ Some might argue that, even if the drone war constitutes terrorism, the war may still be justified because of the continuing threat posed by Islamic terrorism. While I do not have space here to address the long-standing debate about whether terrorism can be justified (see Primoratz 2018 for 


\section{Conclusion: terrorism from the victim's point of view}

Terrorism, as characterised by Rodin as the use of force against those who should not have force used against them, is a morally abhorrent practice. The moral abhorrence of terrorism is shared by most writers on terrorism, including myself, and is reflected in common usages of the term. Yet, in this chapter I have argued that two forms of state violence-police control technologies and drone warfare - are forms of terrorism, despite rarely if ever being described by that word. I have shown that the terrorist nature of these forms of violence is hidden by features of the technologies

an overview of the debate), this argument fails to justify the drone war because Islamic terrorism does not now (and arguably never did - see Jackson 2005, Michaelson 2012, and Wolfendale 2016) pose the kind of existential threat that would be necessary to justify a resort to terrorism, (see, for example, Primoratz 2013). Indeed, white supremacist terrorism arguably poses a greater threat to the lives of US citizens than Islamic terrorism. For example, the F.B.I. director Christopher Wray described "racially motivated violent extremism" as a "national threat priority" equal to the threat from the Islamic State, and when the New Jersey Office of Homeland Security and Preparedness issued its terrorism threat assessment for 2020, "[t]he threat level from violent, homegrown extremists, and specifically white supremacists, was marked in red as the top category: 'High.' The threat from the Islamic State, Al Qaeda and their ilk was demoted to third, in green: 'Low."' (MacFarquhar 2020). 
themselves, the subjectivity of their use, and by the dominant narratives accompanying them. The narratives of efficiency, neutrality, and precision masquerade as moral values and serve to normalise and justify these forms of violence and mark out those subjected to them as deserving of violent treatment. To understand the terrorist nature of these practices, therefore, we must reject the point of view that treats technologies of violence as neutral objects and shift our focus to the experiences of those who are subjected to them. This should always be our starting point when asking whether a practice is a form of terrorism. Such a victim-centred approach to terrorism would destabilise the power dynamics that privilege the perspectives of users and designers of technologies of violence and allow a better understanding of the nature of terrorism and the ways in which commonly accepted forms of state violence might themselves be forms of terrorism. 


\section{References}

Amoore, Louise. "Algorithmic War: Everyday Geographies of the War on Terror." Antipode 41, no. 1: 49-69.

Atherton, Kelsey D. 2020. "Trump Inherited the Drone War but Ditched Accountability: Only a single formal check remains on U.S. killings worldwide." Foreign Policy, May 22, 2020. Available at https://foreignpolicy.com/2020/05/22/obama-drones-trump-killings-count/

Bacchini, Fabio, and Ludovica Lorusso. 2019. "Race, again: how face recognition technology reinforces racial discrimination." Journal of Information, Communication and Ethics in Society 17, no. 3: 321-35.

Benjamin, Ruha. 2019. Race After Technology. Cambridge, UK: Polity Press.

Brettschneider, Corey. 2007. "The rights of the guilty: punishment and political legitimacy." Political Theory 35, no. 2: 175-99.

Center for Civilians in Combat and Columbia Law School Human Rights Clinic. 2012. The Civilian Impact of Drones: Unexamined Costs, Unanswered Questions. New York: Columbia University.

Coeckelbergh, Mark. 2013. "Drones, information technology, and distance: mapping the moral epistemology of remote fighting." Ethics and Information Technology 15: 87-98. 
Cooper, Helene, and Eric Schmitt. 2021. "U.S. Airstrikes in Syria Target Iran-Backed Militias That Rocketed American Troops in Iraq.' The New York Times, February 25, 2021. https://www.nytimes.com/2021/02/25/us/politics/biden-syria-airstrike-iran.html

Crawford, Neta. 2020. “Afghanistan's Rising Civilian Death Toll Due to Airstrikes, 2017-2020.” The Costs of War project, Brown University, December 20, 2020. https://watson.brown.edu/costsofwar/files/cow/imce/papers/2020/Rising\%20Civilian\%20Death \%20Toll\%20in\%20Afghanistan_Costs\%20of\%20War_Dec\%207\%202020.pdf

Criado-Perez, Caroline. 2019. "The deadly truth about a world built for men - from stab vests to car crashes." The Guardian, February 23, 2019. https://www.theguardian.com/lifeandstyle/2019/feb/23/truth-world-built-for-men-car-crashes

Cummings, M. L. 2012. “Automation Bias in Intelligent Time Critical Decision Support Systems.” AIAA Ist Intelligent Systems Technical Conference, June 19, 2012. https://arc.aiaa.org/doi/10.2514/6.2004-6313

Cunneen, Chris. 2020. “'The Torment of Our Powerlessness': Police Violence Against Aboriginal People in Australia." Harvard International Review, September 30. https://hir.harvard.edu/policeviolence-australia-aboriginals/ 
Dobos, Ned. 2020. Ethics, Security, and the War-Machine: The True Cost of the Military. Oxford: Oxford University Press.

Edwards, Hedwig Lee, and Michael Esposito. 2019. "Risk of being killed by police use of force in the United States by age, race-ethnicity, and sex." Proceedings of the National Academy of Sciences 116, no. 34: 16793-98.

Gartenstein-Ross, Daveed, Colin P. Clarke, and Matt Shear. 2020. "Terrorists and Technological Innovation." Lawfare, February 2, 2020. https://www.lawfareblog.com/terrorists-andtechnological-innovation

Gelzer, Joshua A., Karen Kornbluh, and Nicholas Rasmussen. 2019. “Tech Companies Must Fight White Supremacy, Regardless of Political Dangers." Lawfare, August 7. https://www.lawfareblog.com/tech-companies-must-fight-white-supremacy-regardless-politicaldangers

Hankerson, David, Andrea R. Marshall, Jennifer Booker, Houda El Mimouni, Imani Walker, and Jennifer A. Rode. 2016. “Does Technology Have Race?” CHI'16 Extended Abstracts, May 0712, San Jose, CA, USA.

Henschke, Adam, and Timothy Legrand. 2017. "Counterterrorism policy in liberal-democratic societies: locating the ethical limits of national security." Australian Journal of International Affairs 17, no. 5: 544-61. 
Hetey, Rebecca C. and Jennifer L. Eberhardt. 2014. "Racial Disparities in Incarceration Increase Acceptance of Punitive Policies." Psychological Science 25, no. 10: 1949-54.

International Human Rights and Conflict Resolution Clinic at Stanford Law School and Global Justice Clinic at NYU Law School. 2012. Living Under Drones: Death, Injury, and Trauma to Civilians from US Drone Practices in Pakistan. https://www-cdn.law.stanford.edu/wpcontent/uploads/2015/07/Stanford-NYU-Living-Under-Drones.pdf

Jackson, Richard. 2005. Writing the War on Terrorism: Language, Politics, and Counterterrorism. Manchester, UK: Manchester University Press.

Kaag, John and Sarah Kreps. 2014. Drone Warfare. Cambridge, UK: Polity Press.

Kershnar, Stephen. 2013. “Autonomous Weapons Pose No Moral Problems.” In Killing by Remote Control: The Ethics of an Unmanned Military, edited by Bradley Jay Strawser, 229-46. New York: Oxford University Press.

Killmister, Suzy. 2008. "Remote Weaponry: The Ethical Implications." Journal of Applied Philosophy 25, no. 2: 121-33.

Latour, Bruno. 2005. Reassembling the Social: An Introduction to Actor-Network Theory. Oxford: Oxford University Press. 
Levin, Sam. 2020. 'IIts not about bad apples': how US police reforms have failed to stop brutality and violence." The Guardian, June 16, 2020. https://www.theguardian.com/usnews/2020/jun/16/its-not-about-bad-apples-how-us-police-reforms-have-failed-to-stop-brutalityand-violence

Liao, Shen-yi, and Bryce Huebner. 2020. "Oppressive Things." Philosophy \& Phenomenological Research, online first.

https://0-onlinelibrary-wiley.com.libus.csd.mu.edu/doi/full/10.1111/phpr.12701\#reference

Linders, Annulla, Shobha Pai Kansal, Kyle Sharpe, and Samuel Oakley. 2020. "The Promises and Perils of Technological Solutions to the Troubles with Capital Punishment." Humanity \& Society, July 17.

https://journals.sagepub.com/doi/abs/10.1177/0160597620932892?journalCode=hasa1-30.

Lucas, George. 2013. "Engineering, Ethics, and Industry: The Moral Challenges of Lethal Autonomy." In Killing by Remote Control: The Ethics of an Unmanned Military, edited by Bradley Jay Strawser, 211-28. New York: Oxford University Press.

MacFarquhar, Neil. 2020. “As Domestic Terrorists Outpace Jihadists, New U.S. Law Is Debated.” New York Times, February 25, 2020. https://www.nytimes.com/2020/02/25/us/domesticterrorism-laws.html 
Maguire, Edward R. 2015. "New Directions in Protest Policing." Saint Louis University Public Law Review 35, no. 1: 67-108.

Marx, Leo. 1997. “Technology: The Emergence of a Hazardous Concept.” Social Research 64, no. 3: $965-88$.

McReynolds, Phillip. 2005. "Terrorism as a Technological Concept: How Low versus High Technology Defines Terrorism and Dictates Our Responses.” In Philosophy 9/11: Thinking About the War on Terrorism, edited by Timothy Shanahan, 69-93. Peru, Illinois: Open Court.

Michaelson, Christopher. 2012, “The Triviality of Terrorism.” Australian Journal of International Affairs, 66, no. 4: 431-49.

Perry, Andrew M., David Harshbarger, Carl Romber, and Kristian Thymianos. 2020. "To add value to Black communities, we must defund the police and prison systems." Brookings.edu, June 11, 2020. https://www.brookings.edu/blog/how-we-rise/2020/06/11/to-add-value-to-blackcommunities-we-must-defund-the-police-and-prison-systems/

Primoratz, Igor. 2013. Terrorism: A Philosophical Investigation. Cambridge, UK: Polity Press.

Primoratz, Igor, 2018. "Terrorism." The Stanford Encyclopedia of Philosophy, Winter 2018, Edition, Edward N. Zalta (ed.). https://plato.stanford.edu/archives/win2018/entries/terrorism/ 
Qaurooni, Danial, and Hamid Ekbia. 2017. "The "enhanced" warrior: drone warfare and the problematics of separation." Phenomenology and the Cognitive Sciences 16, no. 1: 53-73.

Regan, Milton C. "Citizens, Suspects, and Enemies: Examining Police Militarization." Texas National Security Review, Winter 2020/2021. https://tnsr.org/2020/12/citizens-suspects-andenemies-examining-police-militarization/.

Rejali, Darius. 2003. "Modern torture as civic marker: solving a global anxiety with a new political technology." Journal of Human Rights 2, no. 2: 153-71.

Rhodes, Lorna. 2007. "Supermax as a Technology of Punishment." Social Research 74, no. 2: $547-66$

Rodin, David. 2004. “Terrorism Without Intention.” Ethics 114, no. 4: 752-71.

Savage, Charlie and Eric Schmitt. 2021. "Biden Secretly Limits Counterterrorism Drone Strikes Away from War Zones." The New York Times, March 3, 2021. https://www.nytimes.com/2021/03/03/us/politics/biden-drones.html

Schwarz, Elke. 2018. "Technology and Moral Vacuums in Just War Theorizing." Journal of International Political Theory 14, no. 3: 280-98. 
Schwarz, Ocscar. 2020. "After the protests, lingering trauma: the scars of 'non-lethal' weapons." The Guardian, August 12, 2020. https:/www.theguardian.com/world/2020/aug/12/george-floydprotests-lingering-trauma-non-lethal-weapons-scars

Sharkey, Noel. 2010. "Saying 'No!' to Lethal Autonomous Targeting." Journal of Military Ethics 9, no. 4: 369-83.

Sierra-Arévalo, Michael. 2019. “Technological Innovation and Police Officers' Understanding and Use of Force." Law \& Society Review 53, no. 2: 420-51.

Skerker, Michael, Duncan Purves, and Ryan Jenkins. 2020. “Autonomous Weapons Systems and the Moral Equality of Combatants.” Ethics and Information Technology 22, no. 3: 197-209.

Sparrow, Robert. 2007. “Killer Robots.” Journal of Applied Philosophy 24, no. 1: 63-77.

Sparrow, Robert. 2013. "War Without Virtue?" In Killing by Remote Control: The Ethics of an Unmanned Military, edited by Bradley Jay Strawser, 84-105. New York: Oxford University Press,

Steinhoff, Uwe. 2013. “Killing Them Safely: Extreme Asymmetry and Its Discontents.” In Killing by Remote Control: The Ethics of an Unmanned Military, edited by Bradley Jay Strawser, 179-210. New York: Oxford University $\quad$ Press. 
Strawser, Bradley Jay, editor. 2013a. Killing by Remote Control: The Ethics of an Unmanned Military. New York: Oxford University Press.

Strawser, Bradley Jay. 2013b. "Introduction: The Moral Landscape of Remote Weapons." In Killing by Remote Control: The Ethics of an Unmanned Military, edited by Bradley Jay Strawser, 3-24. New York: Oxford University Press.

Swartzer, Steven. 2019. "Race, Ideology, and the Communicative Theory of Punishment." Philosophers' Imprint 19, no. 53: 1-22. p. 11

UN News. 2019. "New technologies, artificial intelligence aid fight against global terrorism." https://news.un.org/en/story/2019/09/1045562

van der Linden, Harry. 2016. “Arguments against Drone Warfare with a Focus on the Immorality of Remote Control Killing and "Deadly Surveillance"." Radical Philosophy Review 19, no. 2 : $331-58$.

Verbeek, Peter-Paul. 2011. Moralizing Technology: Understanding and Designing the Morality of Things. Chicago: University of Chicago Press.

Walzer, Michael. 2001. "Excusing Terror." The American Prospect, November 5. https://prospect.org/features/excusing-terror/ 
Williams, Joseph P. 2021. "The U.S. Capitol Riots and the Double Standard of Protest Policing." US News, January 12. https://www.usnews.com/news/national-news/articles/2021-01-12/the-uscapitol-riots-and-the-double-standard-of-protest-policing

Wolfendale, Jessica. 2016. "The Narrative of Terrorism as an Existential Threat.” In The Routledge Handbook of Critical Terrorism Studies, edited by Richard Jackson, 114-124. Abingdon, UK: Routledge.

Woodside, Stephen N. 2013. "Unintentional Terrorism? An Objection to David Rodin's 'Terrorism without Intention'.” Journal of Military Ethics 12, no. 3: 252-62. 